\title{
A rapid Soxhlet and mini-SPE method for analysis of polycyclic aromatic hydrocarbons in atmospheric particles
}

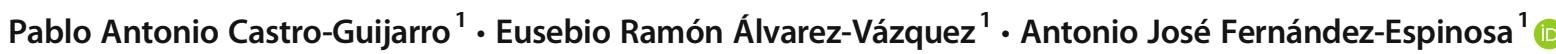

Received: 13 January 2021 / Accepted: 20 January 2021 / Published online: 16 February 2021

(C) Springer-Verlag GmbH Germany, part of Springer Nature 2021

\begin{abstract}
An analytical method was validated with two reference materials of polycyclic aromatic hydrocarbons in atmospheric particles. Standard reference materials (SRMs) were incorporated into the matrix of unexposed cut quartz filters. The methodology was previously designed and extraction of polycyclic aromatic hydrocarbons (PAHs) from fortified filters was based on a rapid lowcost method, for a low consumption of volume and time. The optimisation combined a low-volume Soxhlet apparatus used in hot Soxhlet mode with a quick clean-up by solid-phase extraction with special cartridges. The quantification of target compounds was performed by gas chromatography/mass spectroscopy in SIM mode. Temperatures of injector and oven program of the GCMS were also optimised. Experimental variables of both systems were successfully optimised and validated, achieving a robust analytical methodology.
\end{abstract}

Keywords Polycyclic aromatic hydrocarbons $\cdot$ Atmospheric particles $\cdot$ Reference materials $\cdot$ Gas chromatography $\cdot$ Clean-up . Validation

\section{Introduction}

Polycyclic aromatic hydrocarbons (PAHs) are lipophilic compounds with important carcinogenic risk. These hazardous hydrophobic organic compounds (HOCs) led international organisations to establish policies for the environment [1] and indoor air [2]. The European Commission exposed a wide toxicological guidance since the 2001 position paper [3] to the Europe 2020 strategy [4]. Similar measures were taken by other European organizations [5]. In the atmospheric environment, PAH emissions are well known, as they originated from car exhausts [6], domestic combustion [7], industrial activities [8], agriculture activities [9] and natural sources [10], such as biomass burning [11]. Determination of low levels of PAHs in complex matrices such as atmospheric particles leads to a search for accurate analytical methodologies, which need to be optimised and validated with recognized material references.

Antonio José Fernández-Espinosa

anjose@us.es

1 Department of Analytical Chemistry, Faculty of Chemistry, University of Sevilla, C. Profesor García González 1, Scientific Campus of Reina Mercedes, 41012 Sevilla, Spain
Traditional extraction procedures for PAHs involve many techniques, such as direct extraction with organic solvents, sonication and Soxhlet extraction [12]. In order to speed up sample preparation, new methodologies such as accelerated solvent extraction [13] or microwave-assisted solvent extraction [14] or ultrasound-assisted solvent extraction [15] have been developed, saving processing time and solvent consumption. However, these new techniques are expensive. Soxhlet extraction represents an inexpensive method for solid samples, nevertheless is rather time-consuming and requires high solvent consumption. An improved Soxhlet technique, called hot Soxhlet, heats the extractor body at lower temperature than the boiling point of solvents to keep it in the liquid state [16]. Additionally, after extraction step, it needed purification steps by solid-phase extraction techniques like packed columns of silica, Florisil@, alumina or mixtures [17].

Therefore, the aim of this paper is to optimise and validate a low-cost and rapid extraction methodology with low time and solvent consumption. The method was based on an improved and more rapid Soxhlet extraction plus an improved, short and more efficient SPE technique for the 16 PAHs included in the US EPA priority pollutant list [18] in airborne particles.

Regarding the validation process, suitable certified reference materials should be used, but it is much better with two references [19] to confirm the suitability of the method. 
Additionally, the reference material was mixed with small pieces of unexposed filter, taking the mixture as a new reference for the same matrix of real samples of particles, which are collected on filters during the sampling. This spiking technique constituted an innovative idea in validation techniques. The relevance of the work is the fact that many modern techniques that reduce solvent volume and time consumption are costly when there is currently a global crisis due to SARSCoV-2.

\section{Material and methods}

All solvents used in the present study were of analytical and chromatographic grade.

\section{Optimisation of the new procedure: extraction, purification and quantification}

We validated in 2005 a five-stage analytical procedure for PAHs in airborne particles using the NIST 1649a (National Institute of Standard and Technology, Gaithersburg, MD, USA) [20] where extraction was performed by Soxhlet with $250 \mathrm{~mL}$ of solvent for $10 \mathrm{~h}$. Also, we optimised in $2016 \mathrm{a}$ fourstage procedure for fat in olive fruits [21] using $100 \mathrm{~mL}$ of solvent for $2.5 \mathrm{~h}$. The proposed methodology reduced the method to only two stages before GC quantification, reducing time of extraction and volume consumption. Thus, optimisation of this new method was structured as follows:

\section{Optimisation of the extraction stage}

Optimisation of PAH extraction was done by intercomparing three experiments using three Soxhlet apparatus, with solvent volumes of $250 \mathrm{~mL}$ [21], $100 \mathrm{~mL}$ [18] and $25 \mathrm{~mL}$. The lower the volume of the extractor body, the lower the time of extraction.

For these experiments, $100 \mathrm{mg}$ of standard reference materials (SRM) 1649a was added to each extractor body over onequarter of unexposed QM/A quartz filters of $4 \times 5$ in. (Whatman International, Maidstone, England) cut in small pieces of $0.25 \mathrm{~cm}^{2}\left(0.04 \mathrm{in}^{2}\right)$. Previously, quartz filters were heated in a muffle furnace at $500{ }^{\circ} \mathrm{C}$ for $2 \mathrm{~h}$ to remove residual organic traces. The mixture employed was a 5:1 acetone/ methylene chloride (Merck, Darmstadt, Germany) mixture including pyrene-d10 (Dr. Ehrenstorfer GmbH, Augsburg, Germany) as deuterated surrogate standard. Volumes of organic extracts (around $250 \mathrm{~mL}$ and $100 \mathrm{~mL}$ ) were reduced by rotary evaporation and then until $2 \mathrm{~mL}$ inside the test tubes by slow nitrogen concentration. Purification and quantification stages were carried out for the time being as in the 2005 validation [21]. Extracts of $25 \mathrm{~mL}$ extractor body were nitrogen-concentrated directly. After this volume optimisation, the time of extraction was then minimized on the best Soxhlet system obtained from 250, 100 and $25 \mathrm{~mL}$.

\section{Optimisation of the purification stage}

The process of analyte isolation requires a sample clean-up stage to remove interferences. The extracts of filter from the extraction stage were purified comparing the OCC technique (open-column adsorption liquid chromatography) and the SPE technique in normal phase. In the OCC, alumina/silica (from Merck) was used as adsorbent [21], and in the SPE, miniSpe-ed Plus silica gel cartridges (Applied Separations, Allentown, PA, USA) were proposed. SPE allows isolating PAHs from a sample through the same chemical principles of column chromatography but with low consumption of solvent and quickness.

The OCC technique was performed in glass columns $(30 \mathrm{~cm} \times 1 \mathrm{~cm})$ filled with $1 \mathrm{~g}$ of each alumina/silica gel (top/bottom), conditioning it with $30 \mathrm{~mL}$ of $\mathrm{n}$-hexane (from Merck). The extract ( $2 \mathrm{~mL}$ ) was transferred to the top and the non-polar fraction was eluted with other $2 \mathrm{~mL} \mathrm{n}$-hexane, and $4 \mathrm{~mL}$ was discarded. The aromatic fraction was eluted with $7 \mathrm{~mL}$ of $20 \%$ methylene chloride in n-hexane and nitrogen concentration of $<1 \mathrm{~mL}$ - adding here the deuterated standard mixture - and making up to $2 \mathrm{~mL}$ into a chromatographic vial.

SPE technique with miniSpe-ed Plus silica gel cartridges was performed in a Varian vacuum manifold (Varian Inc., Scientific Instruments; Palo Alto, CA, USA). Each cartridge $(450 \mathrm{mg} / 1 \mathrm{~mL})$ was conditioned with $1.5 \mathrm{~mL}$ of $\mathrm{n}$-hexane and $1.5 \mathrm{~mL}$ methylene chloride. Then, for the aliphatic fraction, $2 \mathrm{~mL}$ of extract plus a few microlitres of deuterated internal standards (ISs mix) were loaded and eluted with $3 \mathrm{~mL}$ of $\mathrm{n}$ hexane at a flow of $0.3-0.5 \mathrm{~mL} \mathrm{~min}^{-1}$ (higher elution speeds lead to low retention volume), and then it was discarded. Then, $3 \mathrm{~mL}$ of methylene chloride was used for eluting PAHs into a 2-mL vial. The chromatographic vial was located inside the vacuum manifold assisting it with a flow of nitrogen. So, a slow nitrogen concentration stage was not necessary.

\section{Optimisation of the quantification: GC/MS experimental conditions}

The sixteen PAHs listed as priority air pollutants by the US EPA [18] were identified and quantified using gas chromatography (Agilent Series 6890A, Santa Clara, CA, USA) with mass spectrometry (Agilent Series 5973N). A capillary column of (5\%-phenyl)-methylpolysiloxane (low polarity) was used (HP-5ms, $30 \mathrm{~m} \times 0.25 \mathrm{~mm}$ i.d. $\times 0.25 \mu \mathrm{m}$ film thickness) from Agilent Technologies. Helium ( $99.9995 \%$ purity) as carrier gas was operated at constant pressure.

Chromatograms obtained at different temperatures of the injector and different optimised oven programs were 
compared. These temperatures were systematically optimised by using an orthogonal design approach. First, the inlet temperature was tested at $250,260,270$ and $280{ }^{\circ} \mathrm{C}$ with the rest of the instrumental conditions fixed. Second, the oven temperature program was optimised in order to obtain the best resolution and separation of chromatographic peaks. Three temperature programs were tested according the following conditions:

$\operatorname{PrA}$ : The initial temperature of $60^{\circ} \mathrm{C}$ was kept for $1 \mathrm{~min}$, then it rose to $210^{\circ} \mathrm{C}$ at $15^{\circ} \mathrm{C} \mathrm{min}{ }^{-1}$, was kept for $1 \mathrm{~min}$, and finally to $280^{\circ} \mathrm{C}$ at $15^{\circ} \mathrm{C} \mathrm{min}^{-1}$, kept for $25 \mathrm{~min}$. Total time: $41.7 \mathrm{~min}$.

$\operatorname{PrB}$ : The initial temperature of $60^{\circ} \mathrm{C}$ was kept for $2 \mathrm{~min}$, then it rose to $200^{\circ} \mathrm{C}$ at $7{ }^{\circ} \mathrm{C} \mathrm{min}^{-1}$, was kept for $2 \mathrm{~min}$, and finally to $290{ }^{\circ} \mathrm{C}$ at $10^{\circ} \mathrm{C} \mathrm{min}^{-1}$, kept for $35 \mathrm{~min}$. Total time: $68.0 \mathrm{~min}$.

$\operatorname{PrC}$ : The initial temperature of $60^{\circ} \mathrm{C}$ was kept for $1 \mathrm{~min}$, then it rose to $175^{\circ} \mathrm{C}$ at $20^{\circ} \mathrm{C} \mathrm{min}-1$, was kept for $3 \mathrm{~min}$, then it rose to $300^{\circ} \mathrm{C}$ at $5^{\circ} \mathrm{C} \mathrm{min}^{-1}$, kept for $20 \mathrm{~min}$. Total time: $54.8 \mathrm{~min}$.

Once temperatures were optimised, the instrument quantification method [22] required a calibration curve 4-1000 $\mathrm{g} \mathrm{L} \mathrm{L}^{-1}$ [ppb] for each. The chromatographic signal of each PAH was relative to a deuterated PAH of the acenaphtene- $d_{10}$, phenanthrene- $d_{10}$, chrysene- $d_{12}$ and perylene- $d_{10}$ internal standard mixture at $200 \mathrm{ppb}$ (from Dr. Ehrenstorfer). Each peak was identified by the absolute and the relative retention times, and by comparison with the mass spectral library of the instrument [23] using a target ion, primary ion ( $\mathrm{T}$ ) and a qualifier molecular ion (Q) (see Supplementary Information (ESM), Table S1).

\section{Validation of the methodology}

In order to study the accuracy (trueness and precision according ISO [24]), two NIST-certified reference materials for PAHs were used, to cover two levels of concentrations: SRM 1649a-Urban Dust and SRM 1648a-Urban Particulate Matter (from NIST) [19,25]. These studies were developed on SRMs 'with/without' filters. Studies to demonstrate the accuracy of the method included (see ESM) (a) recovery study, (b) $t$ tests and $F$ assays, (c) precision study by Horwitz ratios (HorRat), (d) linearity study, (e) sensitivity, (f) selectivity/ specificity determinations, (g) limits of detection and quantification, (h) ruggedness.

For (a), (b) and (c) studies, twelve replicates of $100 \mathrm{mg}$ of the two SRMs were analysed. Other nine calibration series, which employed PAH standards and internal standards, constituted the base of the (d) to (g) validation studies. All experiments of ruggedness were performed with $100 \mathrm{mg}$ of SRM. All statistics were done in agreement with guidelines for validation of the AOAC (Association of Official Analytical Chemists) [26], the IUPAC (International Union of Pure and Applied Chemistry) [27] and the SANCO-DG (Directorate General for Health and Consumer Affairs at the European Commission) [28].

(a) Recovery study: Recoveries were calculated for $n=12$ replicates analysed in different days and weeks according Eq. (1; see ESM). Each recovery value was compared with the AOAC acceptable recoveries.

(b) $F$ assays and $t$ tests: Hypothesis $F$ tests for the precision and $t$ tests for the trueness were done at $p=0.05$ for the $n=12$ replicates by comparing variances and mean values of the measurements with those certified by the NIST SRMs according Eqs. (2, 3 and 4; see ESM).

(c) Precision study: The study of the intra-laboratory precision was done under reproducibility conditions $\left(\mathrm{RSD}_{\mathrm{R}}\right)$, according to twelve replicates' experiment based on two daily sessions with duplicates $(j=1$ and $j=2$, morning/ afternoon sessions), for $n=1,2$ and 3 days of different weeks (between-days). The expected AOAC values of RSD for reproducibility $\left(E_{R S D}\right)$, the predicted $R_{S D}$ values $\left(\mathrm{PRSD}_{\mathrm{R}}\right)$ and the Horwitz ratio, HorRat, see Eq. (5; see ESM), were used as indicator of precision according the Horwitz or Thompson theories [29, 30].

(d) Linearity $R^{2}, r, L$ and $\mathrm{CV}$ : The linearity study was performed from data of different calibration curves during the validation processes. Coefficient of determination $\left(R^{2}\right)$, the Pearson coefficient of correlation $(r)$, the 'goodness' ( $t$-significance), the percentage $(L)$ of linearity [31] and the 'online linearity' (CV) were calculated according to Eqs. (6 to 10; see ESM).

(e) Sensitivity $\gamma$ and $\delta$ : The PAH sensitivity was determined as the 'sensitivity of calibration' (gamma, $\gamma$ ) and as the 'analytical sensitivity' (delta, $\delta$ ). $\gamma$ is defined as the slope of the regression curve (Eq. 11; see ESM). $\delta$ is the ratio of calibration sensitivity to standard deviation of the slope (Eq. 12; see ESM).

(f) Selectivity: Interferences can be introduced through the sample matrix, the sampling system or the instrument system. To reduce interferences, we evaluated the use of pure solvents, the sample handling with laminar airflow cabinets and the use of blanks. Specifically, cleanup procedures were employed to remove most of these substances. In the case of co-eluting compounds, the mass spectrum can be easier interpreted working in SIM mode.

(g) Limits of detection and quantification, criteria comparison: Limits of detection were essentials and they are evaluated by various criteria. First, both limits were determined based on 1978-IUPAC criteria (Eq. 13; see $\mathrm{ESM})$ from the mean of procedural blanks $\left(\mathrm{LOD}_{\mathrm{Bl}}, \times 3\right.$ 
and $\mathrm{LOQ}_{\mathrm{Bl}}, \times 10, n=8$ ), i.e. matrices containing only $1 \mu \mathrm{L}$ of $50 \mathrm{pg} \mu \mathrm{L}^{-1}$ of the IS mix [26].

Second, limits of detection and quantification were also estimated as instrument detection limit $\left(\mathrm{LOD}_{\mathrm{I}}, \times 3\right.$ and $\mathrm{LOQ}_{\mathrm{I}}, \times 10, n=12$ ) from the standard deviations (Eq. 14; see ESM) of calibration curves (ISO 11843, [32]).

For chromatography, standards with concentration close to $\mathrm{LOD}_{\mathrm{I}}$ were required $(n=12)$. It is the noise detection limit, $\mathrm{LOD}_{\mathrm{N}}(\times 3)$ and $\mathrm{LOQ}_{\mathrm{N}}(\times 10)$ prepared from spiking blank samples: we spiked unexposed cut quartz filters with $1 \mu \mathrm{L}$ of $100 \mathrm{pg} \mu \mathrm{L}^{-1}$ (100 ng of the $16 \mathrm{PAH}$ mix standard and $50 \mathrm{ng}$ of the IS mix). Calculation was from the signal-tonoise ratio $(S / N)[33]$ according to Eq. 15 (see ESM).

Also, the limits were determined according to the method used by the ISO-17025-accredited laboratories. The limit of quantification was estimated from a standard at a near-zero concentration (NZC). Thus, three calibration curves were studied by quadruple at low concentrations $<25 \mu \mathrm{g} \mathrm{L} \mathrm{L}^{-1}$ [ppb]; preparing at high range (HR), 5-25 pg $\mu \mathrm{L}^{-1}$; medium range (MR), $0.5-2.5 \mathrm{pg} \mu \mathrm{L}^{-1}$; and low range (LR), 0.05$0.25 \mathrm{pg} \mu \mathrm{L}^{-1}$. Then, the standard with the lowest concentration (determined with less than $3 \%$ error) is selected as the reference for the limit of quantification $\left(\mathrm{LOQ}_{\mathrm{ZC}}\right)$. The limit of detection $\left(\mathrm{LOD}_{\mathrm{ZC}}\right)$ was estimated as one-half of the quantification limit. Finally, we expressed the method detection limits (MDLs) and method quantification limits (MQLs) as those expressed in $\mathrm{pg} \mathrm{m}^{-3}$ and $\mathrm{ng} \mathrm{g}^{-1}$.

(h) Ruggedness study: The method performance was evaluated using a 'ruggedness test' $[34,35]$ by the Youden method. It was based on the Plackett-Burman orthogonal design of eight experiments and seven factors (L8, $2^{\text {(7- }}$ 4). They included small changes in seven (A-G) chromatographic factors at two levels for each factor (overdefault or high-low) with regard to nominal conditions, affecting to the four following experimental variables:

1. Conditions of the low-volume Soxhlet apparatus: assessment of extraction time (A) and solvent volume (B) used.

2. Conditions of the solid-phase extraction technique: assessment of volume (C) and flow rate (D) of elution.

3. Conditions of the solvent evaporation: assessment of the gas flow strength (E) of the nitrogen-assisted solvent evaporation.

4. Conditions of the chromatographic system: assessment of the injected volume $(\mathrm{F})$ of the sample extract and the final injector temperature $(\mathrm{G})$.

Ruggedness was determined by triplicate with $100 \mathrm{mg}$ of both SRMs according the Hadamard matrix. We then evaluated the variables that best and worst adapted to the small 'accidental' changes.

\section{Results and discussion}

The results for searching the best procedure are shown below. Statistical techniques were ANOVA for intercomparison of the three experiments of extraction, Snedecor-Fisher ( $F$ test) for precision and Student's ( $t$ test) for accuracy and intercomparison of the two purification techniques.

\section{Results of the optimisation}

\section{Extraction stage}

In the intercomparison of the three Soxhlet systems, the extraction time reached $10 \mathrm{~h}$ for the $250 \mathrm{~mL}$ extractor body, and $2.5 \mathrm{~h}$ for those of $100 \mathrm{~mL}$. In the case of extraction at $25 \mathrm{~mL}$, a special mini-Soxhlet system was required: the Quickfit ${ }^{\circledR}$ Soxhlet extractor body with only $20 \mathrm{~mL}$ of siphoning volume. The time of extraction was also optimised here. Procedure for $250 \mathrm{~mL}, 100 \mathrm{~mL}$ and $25 \mathrm{~mL}$ was satisfactorily compared $(n=$ 5) of NIST SRM 1649a.

Firstly, $F$ and $t$ tests $(p=0.05)$ applied to both $250 \mathrm{~mL}$ and $100 \mathrm{~mL}$ series showed no significant difference between them for the 13 PAHs of the SRM (all $F_{\text {calc }}<1.37$ for $F_{\text {crit }}=9.60$ and all $t_{\text {calc }}<1.02$ for $\left.t_{\text {crit }}=2.31, p>0.05\right)$. However, $F$ and $t$ tests applied to both $250 \mathrm{~mL}$ and $25 \mathrm{~mL}$ series and to both $100 \mathrm{~mL}$ and $25 \mathrm{~mL}$ series showed significant differences between $250 \mathrm{~mL}$ or $100 \mathrm{~mL}$ and $25 \mathrm{~mL}$ series (all $F_{\text {calc }}>15.42$ for $F_{\text {crit }}=9.60$ and $t_{\text {calc }}>5.13$ for $\left.t_{\text {crit }}=2.31, p<0.05\right)$. Secondly, ANOVA showed significant differences along the three series of solvent volumes $\left(F_{\text {calc }}=13.31>F_{\text {crit }}=3.26\right.$, $p=0.008)$. In addition, recoveries of the $25 \mathrm{~mL}$ procedure were higher $(+4.3-4.8 \%)$ than those of $250 \mathrm{~mL}$ and $100 \mathrm{~mL}$ $\left(t_{\text {calc }}<0.96\right.$ for $\left.t_{\text {crit }}=2.07, p>0.05\right)$ (Fig. 1). As a result, the Quickfit ${ }^{\circ}$ Soxhlet reduces the required volume of solvent to $25 \mathrm{~mL}$ and it allows a high number of cycles (67-83) and shorter cycles (65-80 s), reducing the total time of extraction to $60 \mathrm{~min}$ (see ESM, Fig. S1).

The low volume $(24-25 \mathrm{~mL})$ of the final extract implies a short duration of the NASE (nitrogen-assisted solvent evaporation), which, additionally, were done inside the vacuum manifold. On the other hand, to further increase the efficiency of the rapid extraction, this was performed under the 'hot Soxhlet' conditions [16].

\section{Purification stage}

After extraction, 24-25 $\mathrm{mL}$ of the extract was concentrated to $2 \mathrm{~mL}$ inside the vacuum manifold before the purification stage. In the clean-up optimisation, both OCC and SPE series 
Fig. 1 Recoveries obtained during the extraction stage. Comparison of the $250 / 100 \mathrm{~mL}$ Soxhlet apparatus with the $25 \mathrm{~mL}$ Quickfit ${ }^{\circ}$ System using SRM $1649 \mathrm{a}$

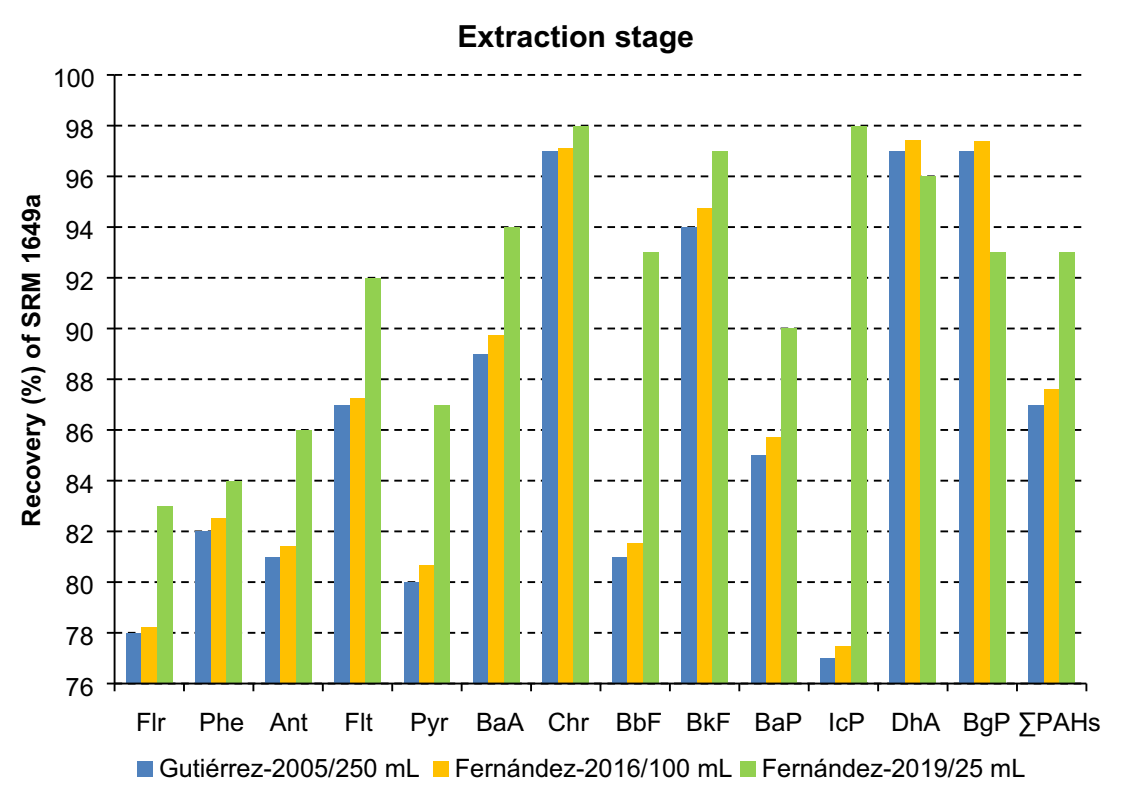

were compared ( $n=5)$ using SRM 1649a (Fig. 2), showing no significant difference between them (all $F_{\text {calc }}<2.06$ for $F_{\text {crit }}=$ 9.60 and $t_{\text {calc }}<1.18$ for $t_{\text {calc }}=2.31, p>0.05$ ). However, recoveries obtained with SPE were higher $(+2.0 \%)$ than for OCC $\left(t_{\text {calc }}<0.81\right.$ for $\left.t_{\text {crit }}=2.07, p>0.05\right)$.

In conclusion, according to the best recoveries obtained with Quickfit ${ }^{\circledR}$ Soxhlet and SPE, the methodology proposed combines the accelerated mini-Soxhlet extraction (AmSE) assisted by hot Soxhlet and the mini-solid-phase extraction with miniSpe-ed (mSPE) assisted with simultaneous nitrogen evaporation, as the rapid Soxhlet and solid-phase extraction (RSE-mSPE) method.

The final RSE-mSPE method was performed in two steps:

First, accelerated mini-Soxhlet extraction on atmospheric filters for $60 \mathrm{~min}$ with $25 \mathrm{~mL}$ of solvent, using the Quickfit ${ }^{\circledR}$
Soxhlet, and second, a mini-solid-phase extraction with silica gel miniSpe-ed on filter extracts for the PAH isolation before GC injection.

\section{Quantification}

\section{GC/MS experimental conditions}

Measurements in the chromatographic system were done using helium at a constant pressure of $20 \mathrm{psi}$, operating in pulsed splitless mode, and injecting $2 \mu \mathrm{L}$ of all the samples, split opened after $30 \mathrm{~s}$. Optimisation of the inlet temperature was tested at $250,260,270$ and $280{ }^{\circ} \mathrm{C}$, fixing the other parameters. All PAHs of 1649a SRM were observed, studying especially the representative compound, benzo $[a]$ pyrene
Fig. 2 Comparison of the recoveries of SRM 1649a between open-column adsorption liquid chromatography and solidphase extraction techniques

\section{Purification stage}

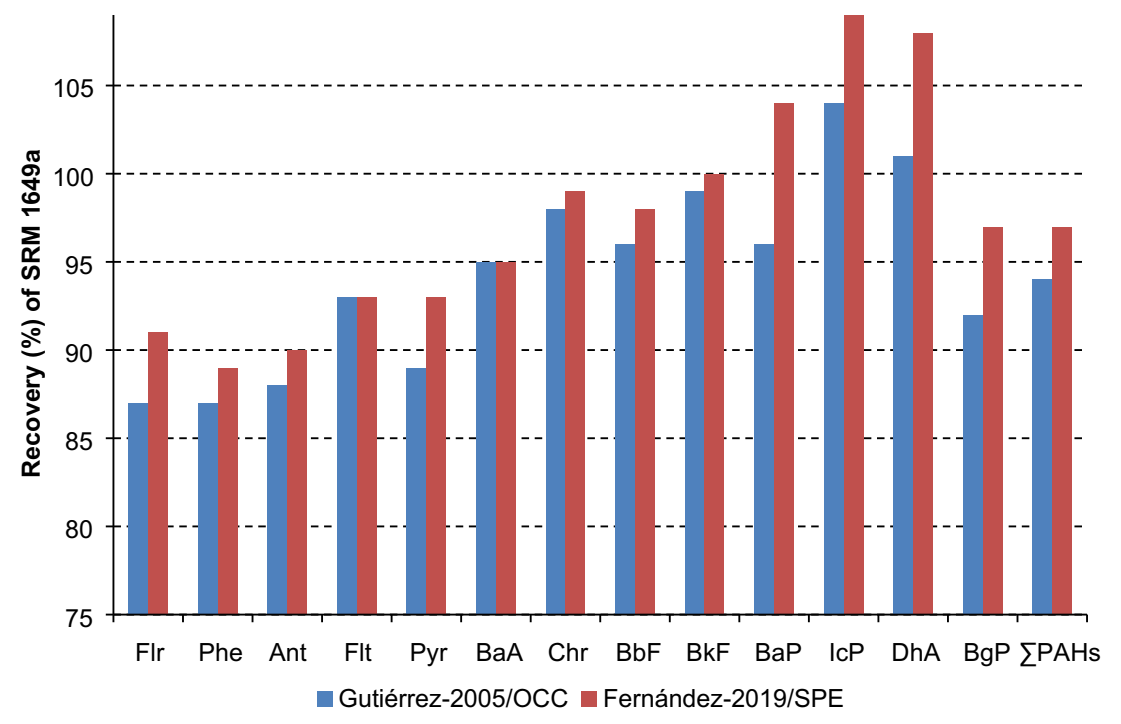


$[B a P]$ as the first marker of total PAHs in scientific reports [36]. When the injector temperature increases from 250 to $280{ }^{\circ} \mathrm{C}$ (see ESM, Fig. S2), the maximum peak area of the $\mathrm{BaP}$ was given to $260^{\circ} \mathrm{C}$; therefore, the temperature of $260^{\circ} \mathrm{C}$ was adopted as the optimal temperature of the injector.

As for the $\operatorname{Pr} A, \operatorname{Pr} B$ and $\operatorname{Pr} C$ oven temperature programs, the three were obtained with good resolution between PAHs. The responses of chromatographic peaks were similar for the three programs tested. However, because the second is too long (68 $\mathrm{min}$ ) and although the first is shorter (42 $\mathrm{min})$, the third program has slightly higher peak resolution for some PAHs than the other two, so the oven temperature program selected was $\operatorname{PrC}(55 \mathrm{~min}): 60^{\circ} \mathrm{C}, 1 \mathrm{~min}, 20^{\circ} \mathrm{C} \mathrm{min}^{-1}$ to $175^{\circ} \mathrm{C}, 3 \mathrm{~min}, 5^{\circ} \mathrm{C} \mathrm{min}{ }^{-1}$ to $300^{\circ} \mathrm{C}$ and hold for $20 \mathrm{~min}$.

Finally, the mass selective detector was operated in electron ionization mode with electron energies of $70 \mathrm{eV}$, being the ion source temperature of $230{ }^{\circ} \mathrm{C}$. To improve sensitivity, quantitative analysis operated in selected ion monitoring (SIM) mode instead of full scan mode. The selected molecular ions of the different PAHs were shown in Table S1 (see ESM).

\section{Results of the validation}

\section{Recovery study}

Recovery and RSD values obtained for both SRMs $(n=12)$ were shown in Table 1. Average recovery for SRM1649a + filter was $R e c=97.9 \%(82.6-107.2 \%)$ and for SRM1648a + filter was $R e c=95.5 \%$ (75.7-104.8\%), with $\mathrm{RSD}=2.0 \%$ for SRM 1649a and 1.5\% for SRM 1648a. All recoveries were 'acceptable' according to the AOAC ranges, showing excellent agreement between measured and certified values. Differences between experiences with/without pieces of filters were negligible, $97.8 \%$ without filters (SRM only) and $98.9 \%$ with filters (as real samples) for SRM 1649a and a similar difference for SRM 1648a.

The aromatic compound with the lowest recovery in SRM 1649a was fluorene (3 rings) with a value of $82.6 \%$ [37]. This was probably due to its volatility (MW $=166$ uma and $P v=$ $0.09 \mathrm{~Pa}$ ). Similar results in SRM 1648a were for acenaphthene and acenaphthylene (76\%, 3 rings, $\mathrm{MW}=152-154$ uma and $P v=0.3-0.9 \mathrm{~Pa})$ and naphthalene $(82 \%, 2$ rings, $\mathrm{MW}=128$ uma and $P v=8.6$ ). On the other hand, the recovery of the extraction method from pyrene- $\mathrm{d}_{10}$ was high with a value of $98.1 \pm 2.8 \%$.

\section{Precision study}

Results of $F$ tests (Table 2) revealed that for all PAHs of both SRMs, differences between variances were not significant $\left(F_{\text {crit }}>F_{\text {calc }}, p=0.05\right)$, except for indeno[1,2,3-cd]pyrene and benzo[ghi]perylene in SRM $1649 \mathrm{a}$; also, $\mathrm{RSD}_{\mathrm{R}}$ values for naphthalene and dibenzo[ $[a h]$ anthracene were higher than those acceptable by the AOAC. Afterwards, $t$ tests showed good results, but not for fluorene in SRM 1649a and acenaphthene, acenaphthylene, benzo[b]fluoranthene and dibenzo[ $a, h]$ anthracene in SRM $1648 \mathrm{a}$, which showed significant differences against true values $\left(t_{\text {crit }}<t_{\text {calc }}, p=0.05\right)$. As a result, from the recoveries (a) and the $t$ tests and $F$ assays (b), we can affirm that the proposed new analytical methodology was traceable to both NIST SRMs without any important systematic error.

The intra-laboratory study (Table 2) showed that values of $\mathrm{RSD}_{\mathrm{R}}$ were lower than AOAC-ERSD $\mathrm{R}_{\mathrm{R}}$ values in all PAHs of SRM 1649a, so they were acceptable and similar than other works [38]. For SRM 1648a, only the $\mathrm{RSD}_{\mathrm{R}}$ values for naphthalene and dibenzo $[a, h]$ anthracene were higher (41.6\% and $47.7 \%)$ than the acceptable (22\% and $14.6 \%)$.

For Horwitz criteria, only naphthalene and dibenzo $[a, h]-$ anthracene have values of Horwitz ratios (HorRat) higher (2.6) than the acceptable values $(0.3-1.3)$ in SRM 1648a. This fact occurred precisely for the two PAHs whose certified RSD values were high, indicating good precision for repeatability but not for reproducibility.

\section{Linearity study}

The linearity of the different calibration curves (4-1000 ppb) can be represented by the goodness or $t$ significance $\left(t_{\text {calc }}\right)$ and by other parameters $\left(r, R^{2}\right.$ and $L$ ). In Table S2 (see ESM), the parameters showed excellent results at $p=0.05$. Coefficients of correlation $r$ were over 0.997 (0.997-0.9997) and significantly different from zero $\left(t_{\text {calc }}>t_{\text {crit }}\right)$ and greater than the critical value 0.707 for a bad linearity. Coefficients of determination $R^{2}$ were over $0.993(0.993-0.9994)$ [37]. Linearity $L(\%)$ were over $95 \%(96.1-98.9 \%)$ and coefficients of variation of the slope $C V_{b}(\%)$ were less than 5\% (1.12-3.91\%).

\section{Sensitivity and selectivity studies}

The values obtained for gamma $\gamma$ sensitivity (ESM Table S2) ranged from the less sensitive, such as $2.5 \times$ $10^{-3} \mu \mathrm{L} \mathrm{pg}^{-1}$ for pyrene and dibenzo $[a, h]$ anthracene, or $2.7-3.5 \times 10^{-3} \mu \mathrm{L} \mathrm{pg}^{-1}$ for fluoranthene, chrysene and benzo[ghi]perylene, to the more sensitive benzo $[b]$ and benzo $[k]$ fluoranthene and naphthalene $(1.3-1.4 \times$ $\left.10^{-2} \mu \mathrm{L} \mathrm{pg}^{-1}\right)$. In terms of delta $\delta$ sensitivity, the most sensitive were naphthalene, benzo $[b]$ and benzo $[k]$ fluoranthene $\left(7.7-8.5 \times 10^{-3}\right)$ against the less sensitive pyrene and fluoranthene $\left(9-10 \times 10^{-4}\right)$, or $1.8-2.1 \times 10^{-3}$ for acenaphthene, fluorene, chrysene, anthracene and dibenzo[ $a, h]$ anthracene.

The selectivity study is necessary in complex matrices, such as filters of airborne particles; thus, it must reduce interferences from real samples and contamination from blanks. Current analysis used selective chemicals that removed 
Table 1 Results of the recovery study using both NIST 1649a and 1648acertified values in $\mathrm{mg} \mathrm{kg}^{-1}$ (mean + standard deviation) for $n=12$ replicates

\begin{tabular}{|c|c|c|c|c|c|c|}
\hline \multicolumn{2}{|c|}{ Certified values in SRMs } & \multicolumn{3}{|c|}{ Experimental values (with filter) } & \multicolumn{2}{|c|}{ Experimental values (without filter) } \\
\hline $\begin{array}{l}\text { Concentration } \\
\left(\mathrm{mg} \mathrm{kg}^{-1}+\mathrm{sd}\right)\end{array}$ & RSI & $\begin{array}{l}\text { Concentration } \\
\left(\mathrm{mg} \mathrm{kg}^{-1}+\mathrm{sd}\right)\end{array}$ & $\operatorname{RSD}(\%)$ & 6) & $\begin{array}{l}\text { Concentration } \\
\left(\mathrm{mg} \mathrm{kg}^{-1}+\mathrm{sd}\right)\end{array}$ & $\operatorname{RSD}(\%) \quad \mathrm{R}$ \\
\hline
\end{tabular}

\begin{tabular}{|c|c|c|c|c|c|c|c|c|c|}
\hline \multicolumn{10}{|l|}{ PAH NIST 1649a } \\
\hline Fluorene* & $0.23 \pm 0.05$ & 21.7 & $0.19 \pm 0.03$ & 15.8 & 82.6 & $0.21 \pm 0.02$ & 9.5 & 91.3 & $80-110$ \\
\hline Phenanthrene & $4.1 \pm 0.4$ & 8.9 & $3.9 \pm 0.3$ & 6.6 & 95.2 & $4.0 \pm 0.2$ & 5.8 & 96.4 & $80-110$ \\
\hline Anthracene & $0.43 \pm 0.08$ & 19.0 & $0.44 \pm 0.05$ & 10.7 & 101.9 & $0.43 \pm 0.06$ & 14.3 & 98.6 & $80-110$ \\
\hline Fluoranthene & $6.4 \pm 0.2$ & 2.8 & $6.3 \pm 0.2$ & 3.3 & 98.1 & $6.4 \pm 0.3$ & 3.9 & 98.9 & $80-110$ \\
\hline Pyrene & $5.3 \pm 0.2$ & 4.7 & $5.2 \pm 0.3$ & 6.2 & 97.4 & $5.2 \pm 0.2$ & 4.0 & 98.9 & $80-110$ \\
\hline $\operatorname{Benzo}[a]$ anthracene & $2.21 \pm 0.07$ & 3.3 & $2.15 \pm 0.11$ & 5.1 & 97.2 & $2.1 \pm 0.3$ & 11.9 & 95.2 & $80-110$ \\
\hline Chrysene & $3.05 \pm 0.06$ & 2.0 & $2.98 \pm 0.10$ & 3.2 & 98.0 & $2.90 \pm 0.09$ & 3.0 & 95.0 & $80-110$ \\
\hline Benzo[b]fluoranthene & $6.4 \pm 0.6$ & 9.9 & $6.1 \pm 0.4$ & 6.7 & 95.2 & $6.0 \pm 0.3$ & 5.7 & 92.7 & $80-110$ \\
\hline Benzo $[k]$ fluoranthene & $1.91 \pm 0.03$ & 1.6 & $1.94 \pm 0.05$ & 2.5 & 101.5 & $1.92 \pm 0.07$ & 3.5 & 100.3 & $80-110$ \\
\hline Benzo $[a]$ pyrene & $2.51 \pm 0.09$ & 3.5 & $2.46 \pm 0.14$ & 5.7 & 98.0 & $2.47 \pm 0.12$ & 4.9 & 98.4 & $80-110$ \\
\hline Indeno $[1,2,3-c d]$ pyrene & $3.2 \pm 0.7$ & 22.6 & $3.4 \pm 0.3$ & 8.8 & 106.9 & $3.3 \pm 0.3$ & 8.6 & 102.8 & $80-110$ \\
\hline Dibenzo $[a, h]$ anthracene & $0.29 \pm 0.02$ & 8.0 & $0.27 \pm 0.04$ & 13.8 & 93.1 & $0.26 \pm 0.02$ & 6.8 & 91.3 & $80-110$ \\
\hline Benzo[ghi]perylene & $4.0 \pm 0.9$ & 22.7 & $4.3 \pm 0.3$ & 7.0 & 107.2 & $4.1 \pm 0.4$ & 10.0 & 102.7 & $80-110$ \\
\hline 16 PAH sum** & $40.2 \pm 1.4$ & 46.5 & $39.7 \pm 0.8$ & 30.1 & 97.9 & $39.3 \pm 0.8$ & 28.3 & 97.1 & 90-107 \\
\hline \multicolumn{10}{|l|}{ PAH NIST 1648a } \\
\hline Naphthalene* & $1.2 \pm 0.6$ & 47.2 & $1.0 \pm 0.4$ & 41.6 & 82.1 & $1.1 \pm 0.3$ & 30.4 & 91.1 & $80-110$ \\
\hline Acenaphthylene* & $0.173 \pm 0.012$ & 6.9 & $0.13 \pm 0.02$ & 13.0 & 75.7 & $0.148 \pm 0.011$ & 7.4 & 85.5 & $80-110$ \\
\hline Acenaphthene* & $0.25 \pm 0.08$ & 33.2 & $0.19 \pm 0.06$ & 28.9 & 76.0 & $0.23 \pm 0.03$ & 14.3 & 92.0 & $80-110$ \\
\hline Fluorene* & $0.25 \pm 0.04$ & 13.9 & $0.23 \pm 0.03$ & 11.3 & 91.6 & $0.23 \pm 0.03$ & 11.3 & 91.6 & $80-110$ \\
\hline Phenanthrene & $4.9 \pm 0.2$ & 3.5 & $5.0 \pm 0.2$ & 4.8 & 101.9 & $4.9 \pm 0.2$ & 4.5 & 100.6 & $80-110$ \\
\hline Anthracene* & $0.459 \pm 0.013$ & 2.8 & $0.47 \pm 0.02$ & 3.4 & 101.3 & $0.45 \pm 0.02$ & 4.7 & 96.9 & $80-110$ \\
\hline Fluoranthene & $8.07 \pm 0.14$ & 1.7 & $8.00 \pm 0.2$ & 1.9 & 99.0 & $7.25 \pm 0.11$ & 1.5 & 89.8 & $80-110$ \\
\hline Pyrene & $5.88 \pm 0.07$ & 1.2 & $5.82 \pm 0.10$ & 1.7 & 99.0 & $5.91 \pm 0.12$ & 2.0 & 100.5 & $80-110$ \\
\hline Benzo $[a]$ anthracene & $2.7 \pm 0.2$ & 5.5 & $2.6 \pm 0.2$ & 8.5 & 95.2 & $2.7 \pm 0.3$ & 10.5 & 98.2 & $80-110$ \\
\hline Chrysene & $6.1 \pm 0.1$ & 1.0 & $6.07 \pm 0.10$ & 1.5 & 99.2 & $6.180 \pm 0.011$ & 0.2 & 101.0 & $80-110$ \\
\hline Benzo[b]fluoranthene* & $8.89 \pm 0.05$ & 0.6 & $9.25 \pm 0.04$ & 0.4 & 104.0 & $9.13 \pm 0.13$ & 1.4 & 102.7 & $80-110$ \\
\hline Benzo $[k]$ fluoranthene & $3.0 \pm 0.2$ & 7.9 & $2.9 \pm 0.3$ & 10.2 & 94.1 & $2.9 \pm 0.2$ & 8.2 & 96.4 & $80-110$ \\
\hline $\operatorname{Benzo}[a]$ pyrene & $2.57 \pm 0.10$ & 3.9 & $2.49 \pm 0.13$ & 5.2 & 96.9 & $2.5 \pm 0.2$ & 6.0 & 96.5 & $80-110$ \\
\hline Indeno $[1,2,3-c d]$ pyrene & $4.2 \pm 0.2$ & 4.1 & $4.3 \pm 0.3$ & 5.8 & 103.4 & $4.1 \pm 0.2$ & 4.2 & 97.1 & $80-110$ \\
\hline Dibenzo $[a, h]$ anthracene & $0.4 \pm 0.2$ & 35.7 & $0.4 \pm 0.2$ & 47.7 & 104.8 & $0.40 \pm 0.08$ & 20.0 & 95.2 & $80-110$ \\
\hline Benzo[ghi]perylene & $5.0 \pm 0.2$ & 3.6 & $5.2 \pm 0.3$ & 5.4 & 103.2 & $5.0 \pm 0.2$ & 4.4 & 100.8 & $80-110$ \\
\hline 16 PAH sum** & $54.1 \pm 0.8$ & 40.4 & $54.0 \pm 0.8$ & 52.1 & 96.1 & $53.0 \pm 0.7$ & 28.8 & 96.9 & $90-107$ \\
\hline
\end{tabular}

*Reference values, not certified. SRM 1649a and 1648a

** Values of $\operatorname{RSD}(\%)$ in the 16 PAH sum was extended from the individual ones

interferences and contamination, such as specific cartridges (miniSpe-ed) and solvents of chromatographic grade, and selective instruments, such as gas chromatograph with capillary columns, and a mass spectrometry detector. In the case of coeluting compounds, the MS detector was set in the selected ion monitoring mode (SIM). The clean-up procedure used with miniSpe-ed removes aliphatic hydrocarbons and polar compounds. Besides, analysis of blanks also proved that analytical determinations were free from contaminants. In addition, possible contaminants were reduced by handling all formats of samples inside the laminar air-flow cabinet INDELAB $®$, Model IDL-48 V with a HEPA filter plus a charcoal layer, which ensure a clean air inside the cabinet. Consequently, the methodology resulted free from chemical interferences or at least with interferences controlled.

\section{Limits of detection and quantification}

Limits of detection from blanks $\left(\mathrm{LOD}_{\mathrm{Bl}}\right)$ were lower (4-7 times) than the instrument detection limits $\left(\mathrm{LOD}_{\mathrm{I}}\right)$ and the 
Table 2 Results of the $F$ tests and $t$ tests using both NIST SRM 1649a and 1648a for $n=12$ replicates. Results of the precision study under reproducibility conditions $(R)$ by Horwitz and AOAC criteria

\begin{tabular}{|c|c|c|c|c|c|c|c|c|}
\hline & $\mathrm{RSD}_{\mathrm{R}}$ & $\begin{array}{l}\text { AOAC- } \\
\text { ERSD }_{R}\end{array}$ & $\mathrm{PRSD}_{\mathrm{R}}$ & HorRat & $F_{\text {calc }}$ & $F_{\text {crit }}$ & $t_{\text {calc }}$ & $t_{\text {crit }}$ \\
\hline \multicolumn{9}{|l|}{ PAH NIST 1649a } \\
\hline Fluorene* & 15.8 & 30 & 20.5 & 0.77 & 2.78 & 3.24 & 2.50 & 2.04 \\
\hline Phenanthrene & 6.6 & 14.6 & 13.0 & 0.51 & 2.03 & 3.24 & 1.64 & 2.04 \\
\hline Anthracene & 10.7 & 22 & 18.1 & 0.59 & 3.04 & 3.24 & 0.31 & 2.04 \\
\hline Fluoranthene & 3.3 & 14.6 & 12.1 & 0.27 & 1.36 & 2.76 & 1.72 & 2.04 \\
\hline Pyrene & 6.2 & 14.6 & 12.5 & 0.50 & 1.64 & 2.76 & 1.38 & 2.04 \\
\hline Benzo $[a]$ anthracene & 5.1 & 22 & 14.3 & 0.36 & 2.27 & 2.76 & 1.89 & 2.04 \\
\hline Chrysene & 3.2 & 14.6 & 13.6 & 0.24 & 2.61 & 2.76 & 2.00 & 2.04 \\
\hline $\operatorname{Benzo}[b]$ fluoranthene & 6.7 & 14.6 & 12.2 & 0.55 & 2.44 & 3.24 & 1.50 & 2.04 \\
\hline $\operatorname{Benzo}[k]$ fluoranthene & 2.5 & 22 & 14.5 & 0.17 & 2.50 & 2.76 & 1.99 & 2.04 \\
\hline Benzo $[a]$ pyrene & 5.7 & 22 & 14.0 & 0.41 & 2.63 & 2.76 & 1.22 & 2.04 \\
\hline Indeno $[1,2,3-c d]$ pyrene & 8.8 & 14.6 & 13.3 & 0.66 & 5.76 & 3.24 & 1.20 & 2.05 \\
\hline Dibenzo $[a, h]$ anthracene & 13.8 & 30 & 19.5 & 0.71 & 2.59 & 2.76 & 1.89 & 2.04 \\
\hline Benzo[ghi]perylene & 7.0 & 14.6 & 12.8 & 0.54 & 9.20 & 3.24 & 1.31 & 2.06 \\
\hline 16 PAH sum & 2.0 & 10.6 & 9.2 & 0.22 & 3.24 & 3.24 & 1.17 & 2.05 \\
\hline \multicolumn{9}{|l|}{ PAH NIST 1648a } \\
\hline Naphthalene* & 41.6 & 22 & 16.0 & 2.60 & 1.91 & 3.24 & 1.14 & 2.04 \\
\hline Acenaphthylene* & 13.0 & 30 & 21.7 & 0.60 & 2.01 & 2.76 & 8.19 & 2.04 \\
\hline Acenaphthene* & 28.9 & 30 & 20.5 & 1.41 & 2.28 & 3.24 & 2.22 & 2.04 \\
\hline Fluorene* & 11.3 & 30 & 20.0 & 0.57 & 1.81 & 2.76 & 1.80 & 2.04 \\
\hline Phenanthrene & 4.8 & 14.6 & 12.6 & 0.39 & 1.99 & 2.76 & 1.24 & 2.04 \\
\hline Anthracene* & 3.4 & 22 & 18.0 & 0.19 & 1.51 & 2.76 & 1.16 & 2.04 \\
\hline Fluoranthene & 1.9 & 14.6 & 11.7 & 0.16 & 1.15 & 2.76 & 1.52 & 2.04 \\
\hline Pyrene & 1.7 & 14.6 & 12.3 & 0.14 & 2.04 & 2.76 & 2.00 & 2.04 \\
\hline Benzo $[a]$ anthracene & 8.5 & 22 & 13.9 & 0.61 & 2.15 & 2.76 & 1.99 & 2.04 \\
\hline Chrysene & 1.5 & 14.6 & 12.2 & 0.12 & 2.25 & 2.76 & 1.89 & 2.04 \\
\hline Benzo $[b]$ fluoranthene* & 0.4 & 14.6 & 11.4 & 0.04 & 1.56 & 2.76 & 21.16 & 2.04 \\
\hline Benzo $[k]$ fluoranthene & 10.2 & 22 & 13.7 & 0.74 & 1.46 & 2.76 & 1.90 & 2.04 \\
\hline Benzo $[a]$ pyrene & 5.2 & 22 & 13.9 & 0.37 & 1.69 & 2.76 & 1.96 & 2.04 \\
\hline Indeno $[1,2,3-c d]$ pyrene & 5.8 & 14.6 & 12.8 & 0.45 & 2.16 & 2.76 & 1.89 & 2.04 \\
\hline Dibenzo $[a, h]$ anthracene & 47.7 & 14.6 & 18.1 & 2.64 & 1.96 & 2.76 & 0.31 & 2.04 \\
\hline Benzo[ghi]perylene & 5.4 & 14.6 & 12.5 & 0.43 & 2.42 & 2.76 & 1.97 & 2.04 \\
\hline 16 PAH sum & 1.5 & 10.6 & 8.8 & 0.14 & 1.85 & 2.76 & 0.66 & 2.04 \\
\hline
\end{tabular}

*Reference values, not certified. SRM 1649a and 1648a; the italicized values represent the compounds that exceeded the AOAC limits $R S D_{R}$, relative standard deviation under reproducibility conditions; $A O A C-E R S D_{R}$, expected AOAC values of $\mathrm{RSD}_{\mathrm{R}} ; P_{R S D_{R}}$, predicted RSD $\mathrm{R}_{\mathrm{R}}$ values; HorRat, Horwitz ratio

others (Table 3) due to the purity of the chemicals used. Therefore, a more realistic alternative is a detection limit based on the signal-to-noise ratio $(3 \times S / N)$. As a result, values of the noise detection limits $\left(\mathrm{LOD}_{\mathrm{N}}\right)$ were similar to the instrumental detection limits, that is $\mathrm{LOD}_{\mathrm{Bl}}<<$ $\mathrm{LOD}_{\mathrm{I}} \cong \mathrm{LOD}_{\mathrm{N}}$.

Moreover, as the HR and MR ranges gave good linearity and all NZC standards were determined with accuracy $(<3 \%$ error), we focused on the low range (LR). Thus, at the lowest concentration obtained, we injected 12 replicates of the reference and quantification and detection limits $\left(\mathrm{LOD}_{\mathrm{ZC}}\right.$, onethird of $\mathrm{LOQ}_{\mathrm{ZC}}$ ) were estimated.

In brief, final comparison resulted in $\mathrm{LOD}_{\mathrm{Bl}}<\mathrm{LOD}_{\mathrm{ZC}}<$ $\mathrm{LOD}_{\mathrm{N}} \cong \mathrm{LOD}_{\mathrm{I}}$ and the selected method detection limit (MDL) was the instrumental detection limit $\left(\operatorname{LOD}_{\mathrm{I}}\right)$, expressed as pg $\mu \mathrm{L}^{-1}$ or as $\mathrm{pg} \mathrm{m}^{-3}$ and $\mathrm{ng} \mathrm{g}^{-1}$. Values of Table 3 were lower than other studies [38]. However, Piñeiro-Iglesias et al. [19] reported limits similar for 
Table 3 Limits of detection (LODs, pg $\mu \mathrm{L}^{-1}$ ) for PAHs

\begin{tabular}{|c|c|c|c|c|c|c|c|c|c|c|c|c|}
\hline HAP & $\mathrm{LOD}_{\mathrm{I}}$ & $\mathrm{sd}$ & $\mathrm{LOD}_{\mathrm{Bl}}$ & $\mathrm{sd}$ & $\mathrm{LOD}_{\mathrm{N}}$ & $\mathrm{sd}$ & $\mathrm{LOD}_{\mathrm{ZC}}$ & sd & $\mathrm{MDL}_{\mathrm{A}}$ & sd & $\mathrm{MDL}_{\mathrm{B}}$ & $\mathrm{sd}$ \\
\hline Naphthalene & 0.215 & 0.011 & 0.048 & 0.005 & 0.189 & 0.009 & 0.138 & 0.005 & 1.05 & 0.06 & 4.3 & 0.2 \\
\hline Acenaphthylene & 0.061 & 0.004 & - & & 0.036 & 0.002 & 0.016 & 0.003 & 0.30 & 0.02 & 1.22 & 0.08 \\
\hline Acenaphthene & 0.187 & 0.011 & 0.029 & 0.004 & 0.151 & 0.004 & 0.109 & 0.005 & 0.92 & 0.05 & 3.7 & 0.2 \\
\hline Fluorene & 0.148 & 0.009 & - & & 0.122 & 0.007 & 0.007 & 0.005 & 0.72 & 0.04 & 2.9 & 0.2 \\
\hline Phenanthrene & 0.222 & 0.006 & 0.075 & 0.002 & 0.198 & 0.003 & 0.145 & 0.003 & 1.09 & 0.03 & 4.44 & 0.11 \\
\hline Anthracene & 0.152 & 0.006 & 0.021 & 0.002 & 0.121 & 0.002 & 0.075 & 0.002 & 0.74 & 0.03 & 3.04 & 0.11 \\
\hline Fluoranthene & 0.251 & 0.006 & 0.076 & 0.003 & 0.228 & 0.005 & 0.174 & 0.003 & 1.23 & 0.03 & 5.02 & 0.11 \\
\hline Pyrene & 0.35 & 0.02 & 0.17 & 0.02 & 0.31 & 0.02 & 0.274 & 0.009 & 1.72 & 0.10 & 7.0 & 0.4 \\
\hline Benzo $[a]$ anthracene & 0.093 & 0.005 & - & & 0.070 & 0.003 & 0.015 & 0.005 & 0.45 & 0.02 & 1.85 & 0.11 \\
\hline Chrysene & 0.209 & 0.013 & 0.076 & 0.009 & 0.177 & 0.003 & 0.132 & 0.003 & 1.02 & 0.06 & 4.2 & 0.2 \\
\hline Benzo[b]fluoranthene & 0.044 & 0.003 & - & & 0.017 & 0.004 & 0.009 & 0.004 & 0.213 & 0.013 & 0.87 & 0.05 \\
\hline Benzo $[k]$ fluoranthene & 0.056 & 0.002 & - & & 0.031 & 0.003 & 0.021 & 0.003 & 0.273 & 0.010 & 1.12 & 0.04 \\
\hline Benzo $[a]$ pyrene & 0.110 & 0.007 & - & & 0.071 & 0.005 & 0.032 & 0.002 & 0.54 & 0.03 & 2.19 & 0.13 \\
\hline Indeno[1,2,3-cd]pyrene & 0.102 & 0.006 & - & & 0.061 & 0.003 & 0.025 & 0.002 & 0.50 & 0.03 & 2.04 & 0.12 \\
\hline Dibenzo $[a, h]$ anthracene & 0.100 & 0.006 & - & & 0.062 & 0.005 & 0.023 & 0.003 & 0.49 & 0.03 & 2.00 & 0.11 \\
\hline Benzo $[g h i]$ perylene & 0.122 & 0.005 & - & & 0.099 & 0.005 & 0.044 & 0.002 & 0.59 & 0.02 & 2.43 & 0.10 \\
\hline
\end{tabular}

-: Values of $\mathrm{LOD}_{\mathrm{B} 1}$ could not be estimated due to the absence of the compounds in the procedural blanks

Estimations for instrument detection limit ( $\left.\mathrm{LOD}_{\mathrm{I}}, n=12\right)$, blank detection limit $\left(\mathrm{LOD}_{\mathrm{B}}, n=8\right)$, noise detection limit $\left(\mathrm{LOD}_{\mathrm{N}}, n=12\right)$ zero concentration detection limit $\left(\mathrm{LOD}_{\mathrm{ZC}}, n=12\right)$ and method detection limit $(M D L)$ expressed as concentration in the ambient air $\left(M D L_{A}, \mathrm{pg} \mathrm{m}^{-3}\right)$ and in the solid particulate matter $\left(M D L_{B}, \mathrm{ng} \mathrm{g}^{-1}\right)$

anthracene but not for fluoranthene and pyrene, which were higher than those reported here.

\section{Ruggedness study}

The ruggedness of a procedure must be established for 'inhouse' developed methods [33]. Seven factors (A-G) were tested along four chromatographic conditions:

1. Conditions of the AmSE (accelerated mini-Soxhlet extractor): extraction time of 45 and $75 \mathrm{~min}$ (A) were employed with a solvent volume of 20 and $30 \mathrm{~mL}$ of the solvent mixture (B). Nominal conditions were at $60 \mathrm{~min}$ for $25 \mathrm{~mL}$.

2. Conditions of the SPE technique with miniSpe-ed cartridges: fraction volumes of $2.5 \mathrm{~mL}$ and $3.5 \mathrm{~mL}$ of methylene chloride $(\mathrm{C})$ were collected at flow rates of elution of $0.35 \mathrm{~mL} \mathrm{~min}{ }^{-1}$ and $0.65 \mathrm{~mL} \mathrm{~min}^{-1}$ (D). Nominal conditions were at $3 \mathrm{~mL}$ and

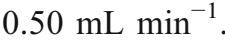

3. Conditions of the gas flow strength for the NASE (nitrogen-assisted solvent evaporation): nitrogen flows of $25 \mathrm{~mL} \mathrm{~min} \min ^{-1}$ and $75 \mathrm{mLin}^{-1}$ (E) were explored. Nominal conditions were at $50 \mathrm{~mL} \mathrm{~min}^{-1}$.

4. Conditions of the chromatographic system: injection volume of $1.0 \mu \mathrm{L}$ and $3.0 \mu \mathrm{L}$ (F) of the sample extract were tested, performing analyte separation at a final injector temperature of $250{ }^{\circ} \mathrm{C}$ and $270{ }^{\circ} \mathrm{C}(\mathrm{G})$. Nominal conditions were injecting $2 \mu \mathrm{L}$ and oven temperature of $260{ }^{\circ} \mathrm{C}$.

The factor variations are shown in Fig. 3. The deviations of chromatographic parameters were below $12.5 \%$ for negative deviations and $5 \%$ for positive ones. Therefore, SRM recoveries were always within the range of AOAC percentages of

Recovery deviation (\%)

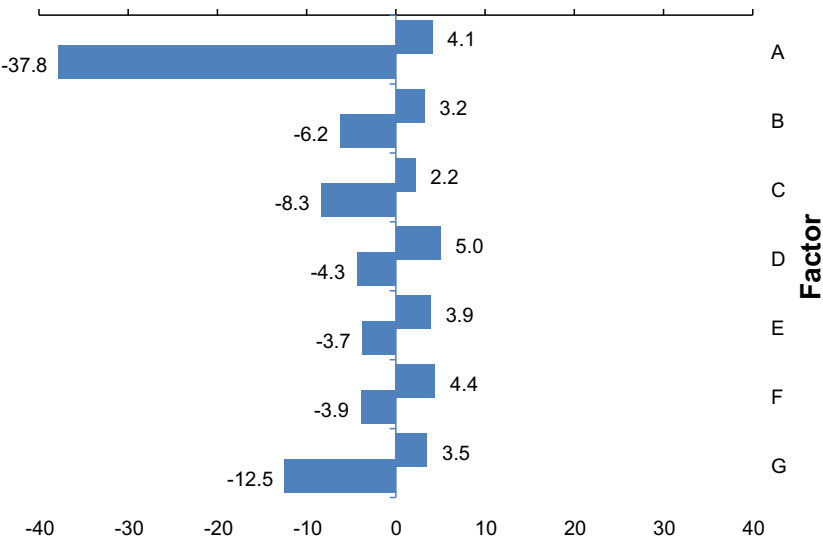

Fig. 3 Results of the ruggedness study. Changes on SRMs recoveries by variation of factors. A: AMSE extraction time; B: solvent extraction volume; C: volume of methylene chloride in SPE; D: flow rate of elution; E: nitrogen flow of NASE; F: injection volume of the extract; $\mathrm{G}$ : injector temperature of GC 
Fig. 4 Analytical methodology validated with two SRMs for PAH determination

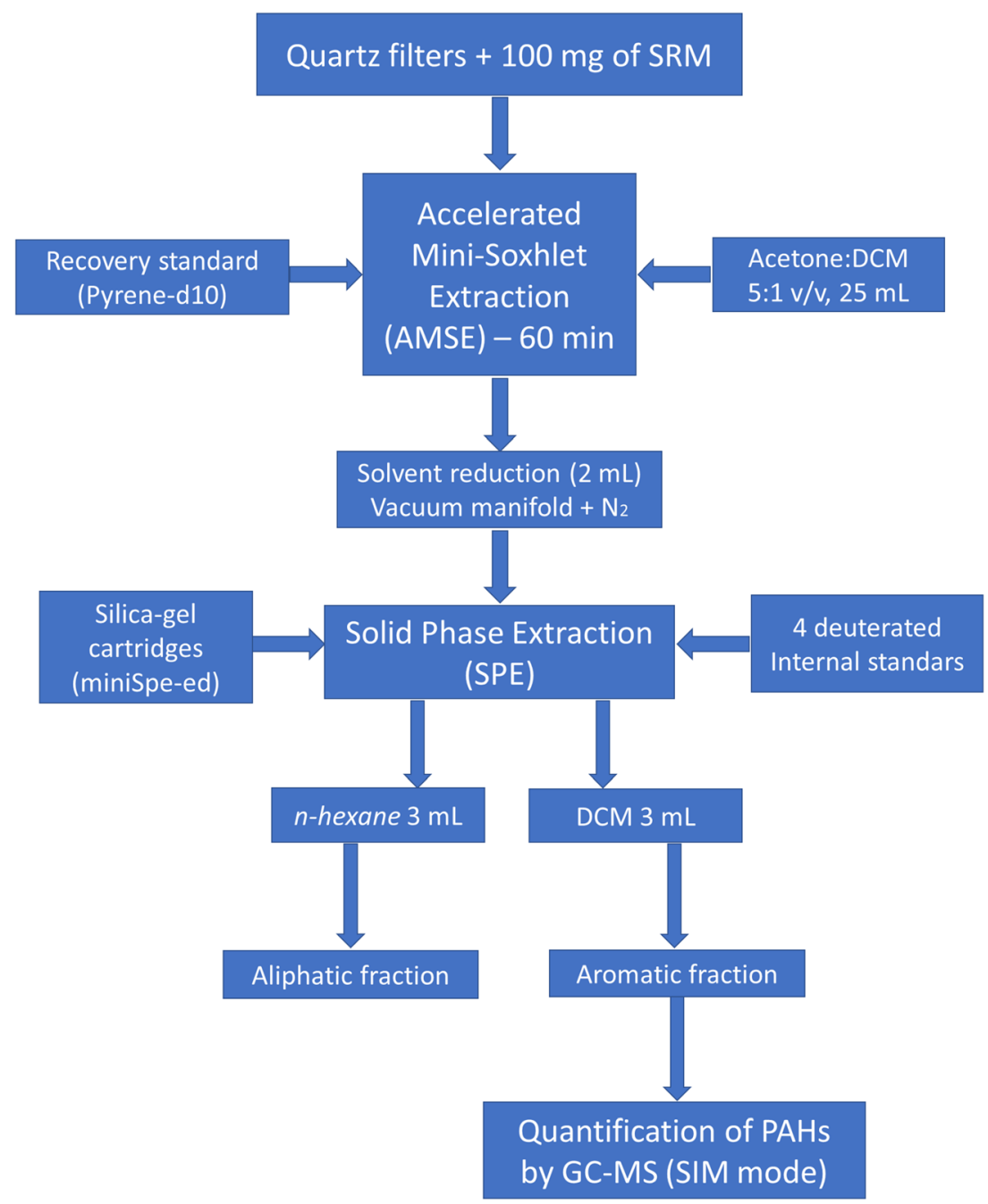

recovery. The only factor that most affects results is factor A (Soxhlet extraction time) when is less than $60 \mathrm{~min}$. Therefore, there were no significant differences in performance of the method as a result of the deliberate changes, implying that our developed method is robust in terms of reliability.

The complete optimised and validated method was (Fig. 4) $100 \mathrm{mg}$ of one-half cut quartz filter of airborne particles was extracted in the AmSE system with $25 \mathrm{~mL}$ of 5:1 acetone/ methylene chloride for $60 \mathrm{~min}$. After quick evaporation until $2 \mathrm{~mL}$ with NASE, the organic extract was purified by $\mathrm{mSPE}$ using a miniSpe-ed cartridge, eluting PAH simultaneously to nitrogen evaporation with $3 \mathrm{~mL}$ of methylene chloride.

\section{Conclusions}

The proposed RSE-mSPE method for extraction of PAHs in atmospheric particles helps in minimizing solvent volume and time extraction. The two main stages optimised AmSE+mSPE and improved the recovery and accuracy of PAH determination. Accelerated mini-Soxhlet extraction system (AmSE) reduced volume consumption in 90\% (10 times), time consumption in 90\% (10 times) and increased recoveries of SRM in 9\%. Mini-solid-phase extraction (mSPE) also reduced time consumption in $90 \%$ ( 9 times) and increased recoveries of SRM in 3\%. The other parameters of validation were successfully assessed with good agreement between certified and reference values, thereby no interferences being by the presence of quartz filters. Thus, it can be stated that the proposed RSE-mSPE methodology is a simple, fast and lowcost method that can be used, combining with GC/MS-SIM, for the determination of PAHs in airborne particulate matter.

Supplementary Information The online version contains supplementary material available at https://doi.org/10.1007/s00216-021-03188-9.

Funding This work would not have been possible without the partial financial assistance of the Environmental Agency of the 'Junta de Andalucía', the Regional Government of Southern Spain, through the different Research Projects on Air Quality provided to our Research Group RNM-294 from 1995 to 2015. 


\section{Declarations}

Conflict of interest The authors declare no conflict of interest.

\section{References}

1. World Health Organization, WHO (2000) Air quality guidelines. 2nd edition. Chap. 5.9. pp. 92-96. Regional Office for Europe. WHO regional publications, European series, No. 91. Copenhagen (Denmark).

2. World Health Organization, WHO (2010) Polynuclear aromatic hydrocarbons. In: WHO Guidelines for indoor air quality. Selected Pollutants. Chap. 6. pp. 289-346. Regional Office for Europe. Copenhagen (Denmark).

3. European Commission, EC (2001) Ambient air pollution by polycyclic aromatic hydrocarbons (PAH). Position Paper. Chap. 5. pp. 47-49. July 2001. Office for Official Publications of the European Communities, Luxembourg.

4. HBM4EU (2018) Scoping document on prioritized substance group: PAHs and air pollutants. 1st edition. Chap. 2. pp. 12-16. December 2018. AUTH Chemical group leader. HBM4EU Project of the European Union's Horizon 2020 programme: Science and policy for a health future. German Environment Agency, Section II 1.2 Toxicology, Health Related Environmental Monitoring.

5. OSPAR Commission (2009) Background document on polycyclic aromatic hydrocarbons (PAHs), update 2009. Hazardous Substances Series. The Executive Secretary. London, United Kingdom.

6. CONCAWE (2001) Automotive emissions of polycyclic aromatic hydrocarbons. After Report 98/55. Vol. 10, No 1, April 2001. Environmental science for European refining. Division of the European Petroleum Refiners Association. CONCAWE, Brussels.

7. OSPAR Commission (2001) Best environmental practice (BEP) for the reduction or prevention of emissions of polycyclic aromatic hydrocarbons (PAHs) from domestic combustion appliances. OSPAR Background Document. The Executive Secretary. London, United Kingdom.

8. Nguyen TNT, Kwon GL, Jung KS, Lee SJ, Choi SD. Spatially high-resolved monitoring and risk assessment of polycyclic aromatic hydrocarbons in an industrial city. J. Haz. Mat. 2020;393:122409 (1-11).

9. Lee BK. Sources, distribution and toxicity of polyaromatic hydrocarbons (PAHs) in particulate matter, air pollution, Vanda Villanyi (Ed.), InTech. 2010

10. Maliszewska B. Sources, concentrations, fate and effects of polycyclic aromatic hydrocarbons (PAHs) in the environment, review. Part a: PAHs in air. Polish J. Environ. Stud. 1999;8:131-6.

11. Luo J, Han Y, Zhao Y, Huang Y, Liu X, Tao S, et al. Effect of northern boreal forest fires on PAH fluctuations across the artic. Environ Poll. 2020;261:114186.

12. Galvao ES, Santos JM, Lima AT, Reis NC Jr, D'Azeredo MT, Stuetz RM. Trends in analytical techniques applied to particulate matter characterization: a critical review of fundaments and applications. Chemosphere. 2018;199:546-68.

13. Maurice AS, Ocampo R, Alleman L, Coddeville P. Tenax-TA spiking approach of thermal desorption coupled to GC-MSMS for the quantification of PAHs in indoor air and dust. Pol Arom Comp. 2017;37:170-7.

14. Yuan, X., You, F., Yong, L., Yang, C., Zhu, L., Hu, B., Liu, T. Rapid determination of 16 polycyclic aromatic hydrocarbons in PM2.5 by microwave assisted extraction-high performance liquid chromatography, Microch. J. 2019;144:391-396.
15. Rodríguez P, Moreda A, Bermejo A, Bermejo P. Ultrasoundassisted solvent extraction (UASE) of total polycyclic aromatic hydrocarbons from mussels followed by spectrofluorimetric determination. Talanta. 2005;66:683-90.

16. Oukebdane K, Portet F, Machour N, Dionnet F, Desbène PL. Comparison of hot Soxhlet and accelerated solvent extractions with microwave and supercritical fluid extractions for the determination of polycyclic aromatic hydrocarbons and nitrated derivatives strongly adsorbed on soot collected inside a diesel particulate filter. Talanta. 2010;82:227-36.

17. Walgraeve, C., Demeestere, K., Dewulf, J., Zimmermann, R., Van Langenhov, H Oxygenated polycyclic aromatic hydrocarbons in atmospheric particulate matter: molecular characterization and occurrence. Atmos Environ 2010;44:1831-1846.

18. EPA, 2014. Priority pollutant list. From toxic and priority pollutants under the clean water act, Washington, DC.

19. Piñeiro M, López P, Vázquez E, Muniategui S, Prada D, Fernández E. Microwave assisted extraction of polycyclic aromatic hydrocarbons from atmospheric particulate samples. Anal Bioanal Chem. 2000;367:29-34.

20. Gutiérrez, A., Fernández, A.J., Ternero, M., Fernández, F. Particlesize distribution of polycyclic aromatic hydrocarbons in the urban air in southern Spain. Anal. Bioanal, Chem. 2005;381:721-736.

21. Fernández-Espinosa AJ. Combining PLS regression with portable NIR spectroscopy to on-line monitor quality parameters in intact olives for determining optimal harvesting time. Talanta. 2016;148: 216-28.

22. EPA. 2018. Method 8270E (SW-846): Semivolatile organic compounds by gas chromatography/mass spectrometry (GC/MS), rev. 6, June 2018, Washington, DC.

23. Wiley/NIST (2017) Wiley Registry®, 11th Edition/NIST 2017, Mass Spectral Library, Mass Spectrometry Data, Mass Spectrometry Data Center. September 2017.

24. ISO (1994) 5725-1:1994. Accuracy (trueness and precision) of measurement methods and results - part 1: General principles and definitions, ISO Geneva.

25. Karthikeyan S, Balasubramanian R, Wei S. Optimisation and validation of a low temperature microwave-assisted extraction method for analysis of polycyclic aromatic hydrocarbons in airborne particulate matter. Talanta. 2006;69:79-86.

26. AOAC International. Guidelines for standard method performance requirements. AOAC official methods of analysis. Gaithersburg, MD: Appendix F; 2016.

27. Thompson M, Ellison SLR, Wood R. Harmonized guidelines for single-laboratory validation of methods of analysis. Pure Appl Chem. 2002;74:835-55.

28. European Commission, EC (2019) SANCO/3030/99 rev. 5. Technical active substance and plant protection products: guidance for generating and reporting methods of analysis in support of preand post-registration data requirements for Annex II (Section 4) of Regulation (EU) No 283/2013 and Annex (Section 5) of Regulation (EU) No 284/2013. Guidance document. Directorate General Health and Consumer Protection 22 March.

29. Thompson L. The Horwitz function revisited. J AOAC Int. 1997;80:676-9.

30. Horwitz, W., Albert, R., Deutsch, M.J. Precision parameters of methods of analysis required for nutrition labeling, part I. major nutrients. J AOAC Int 1990;73:661-680.

31. Cuadros L, García AM, Bosque JM. Statistical estimation of linear calibration range. Anal Lett. 1996;29:1231-9.

32. ISO (2007) ISO11843-2:2007 capability of detection-part 2: methodology in the linear calibration case, ISO Geneva.

33. EPA (2017) Title 40. Protection of environment. Chapter I. EPA. Subchapter D. Water programs. Part 136 - guidelines establishing test procedures for the analysis of pollutants. Appendix B to Part 
136-Definition and procedure for the determination of the method detection limit, Revision 2, 28 August. Washington, DC.

34. Magnusson, B., Ornemark, U. Eurachem guide: the fitness for purpose of analytical methods-a laboratory guide to method validation and related topics. 2nd Edition, Eurachem. 2014.

35. Youden, W.J., Steiner, E.H. Statistical manual of the AOAC- statistical techniques for collaborative tests (by) W.J. Youden. Planning and analysis of results of collaborative tests (by) E.H. Steiner. In: AOAC International (Ed.). Washington D.C., U.S.A., 1975;33-41.

36. Boström CE, Gerde P, Hanberg A, Jernström B, Johansson C, Kyrklund T, et al. Cancer risk assessment, indicators and guidelines for polycyclic aromatic hydrocarbons in the ambient air. Special Report. Environ. Health Perspect. 2002;110:451-88.
37. Li T, Wang Y, Hou J, Zheng D, Wang G, Hu C, et al. Associations between inhaled doses of PM2.5-bound polycyclic aromatic hydrocarbons and fractional exhaled nitric oxide. Chemosphere. 2019;218:992-1001.

38. Resende, R., de Lourdes, Z., Helvécio, C., Menezes, C. Phase distribution of polycyclic aromatic hydrocarbons and their oxygenated and nitrated derivatives in the ambient air of a Brazilian urban area. Chemosphere 2020;250:126223 (1-11).

Publisher's note Springer Nature remains neutral with regard to jurisdictional claims in published maps and institutional affiliations. 